\title{
Research on Double Price Regulations and Peak Shaving Reserve Mechanism in Coal-Electricity Supply Chain
}

\author{
Hongjun Peng, ${ }^{1,2}$ Meihua Zhou, ${ }^{2}$ and Fudong Wang ${ }^{2}$ \\ ${ }^{1}$ College of Economics and Management, Nanjing Forestry University, Nanjing 210037, China \\ ${ }^{2}$ School of Management, China University of Mining and Technology, Xuzhou 221116, China \\ Correspondence should be addressed to Meihua Zhou; mhzhou63@126.com
}

Received 18 October 2013; Revised 9 December 2013; Accepted 9 December 2013

Academic Editor: Matjaž Perc

Copyright (c) 2013 Hongjun Peng et al. This is an open access article distributed under the Creative Commons Attribution License, which permits unrestricted use, distribution, and reproduction in any medium, provided the original work is properly cited.

\begin{abstract}
The game models were used to study the mechanism of coal-electricity price conflict under conditions of double price regulations of coal and electricity. Based on this, the peak shaving reserve mechanism was designed to probe into the countermeasures against the coal-electricity price conflicts. The study revealed that in the boom seasons of coal demand, the initiatives of the coal enterprises to supply thermal coal and the electricity enterprises to order thermal coal are reduced under conditions of double price regulations. However, under the circumstances of coal price marketization, in the boom seasons of coal demand the thermal coal price may go up obviously, the initiatives of the coal enterprises to supply thermal coal are increased, and meanwhile the initiatives of the power enterprises to order thermal coal are decreased dramatically. The transportation capacity constraint of coal supply leads to the evident decrease of the initiatives of coal enterprises for the thermal coal supply. The mechanism of peak shaving reserve of thermal coal may not only reduce the price of coal market but also increase the enthusiasm of the power enterprises to order more thermal coal and the initiatives of the coal enterprises to supply more thermal coal.
\end{abstract}

\section{Introduction}

In China's energy production and consumption structure, coal occupies a leading role, and in the past 20 years, its proportion has maintained at around $70 \%$. China is rich in coal and poor in oil and gas; it determines that coal should be the major energy source for a long period of time [1]. The China's special national situations and the production pattern of electricity determine the special relationship of mutual dependence between coal-electricity enterprises.

The coal-electricity price is dually regulated by Chinese government $[2,3]$. Firstly, the government adopts the transverse dual-track price system for coal; that is, the price of the thermal coal is regulated and the marketoriented price system for other coal not used for generating power is carried out. The government tried to let go the price control of thermal coal since 2002. However, in the process of marketization of thermal coal, the price of the thermal coal is still regulated by government, and there is the dual-track price system in the coal market always.
Facing the ever-increasing price of the thermal coal, National Development and Reform Commission has more than once exerted the temporary intervention on the price of thermal coal since 2008. Secondly, there exists a longitudinal dualtrack price system between coal and electricity. Under the circumstance of lifting the control of the price of thermal coal step by step, the price of the electricity is but strictly regulated by the government; from this, it results in the longitudinal dual-track price system.

Several papers have conducted research on the price regulation in different fields. Arocena et al. [4] analyzed the distribution of benefits between firms and consumers due to the price regulation of the Spanish energy sectors during 1987-1997. Ciarreta and Espinosa [5] measured the impact of regulatory measures on the wholesale market. Coco and de Vincenti [6] studied the possibility that price regulation increases a monopolist's cost efficiency. Weisman [7] revealed that participation by the regulated firm in complementary and competitive markets may serve to reduce investment in quality. Johnsen and Olsen [8] considered that Danish 
default prices are regulated whereas default prices in the other countries are unregulated. The paper analyzed that Danish margins are higher than the competitive Norwegian margins but are earned from a much lower level of consumption. The annual margins earned per consumer are very close in the two countries; it indicated that the Danish regulation is achieving its objective of approaching competitive prices. Wang [9] proposed a grey linear control system for regulating the price of China's real estate and provided the necessary support to assist the relevant management departments with their policy making. Guthrie [10] studied the incentives of regulated firms' investment behavior. Using US long-distance telephone services as an example, Galbi [11] showed the empirical evidence concerning customer acquisition costs, customer switching costs, and churn among service providers can help to inform price regulation. But few papers studied the effect of double price regulation in the supply chain and the countermeasures.

In recent years, the tension of coal-electricity relationship in China is highlighted. The balance of supply and demand of thermal coal is weak, and the conflicts of supply and demand of the thermal coal for a certain region and a certain period of time appear from time to time. Especially since 2002, the price of thermal coal is constantly rising and the competition between enterprises of coal and electricity is becoming more and more frequent and fierce. At the time of hot summer, cold winter, and unexpected natural disasters, the problem stands out extremely serious. Therefore, ration of power supply through simply cutting off power happens frequently.

Ever since 2012, under influence of the macroeconomic situation, the tension situation of the coal-electricity supply seemed to have been relieved; however, along with the improvement of the economic situation gradually, the tension situation of the coal-electricity supply is bound to recur.

As for the reasons of tense supply of coal and electricity, some scholars argued that it is attributable to the unsmooth price system and the regional selfish departmentalism [12]. Other scholars, starting from the perspective of policy conflicts, have conducted researches on the formational mechanism of the tense relationship between coal and electricity in China and pointed out that the multiple policy conflicts contribute immensely to the present tense situation [2]. Researches considered that China's price regulation of coalelectricity gives rise to the serious conflicts between coal and electricity, and this serious conflict further leads to the loss of power enterprises and the uncertainty of the quantity and quality of thermal coal supply $[13,14]$.

As to the countermeasures against the tense situation of the thermal coal supply, researches suggested that when solely depending on the administrative means of the government, they may not fundamentally solve the problems of transaction and price fixing $[12,15]$. It is important to dismiss the existing policy conflicts if the government aims to coordinate the longitudinal transactional relationship in China's coal and electricity enterprises [12]. Some scholars have also conducted assessment on the criticality of the thermal coal supply chain and have built the risk management and control scheme [16]. He et al. [17] through establishing
CGE model have proven that under the linkage mechanism, the ever-increasing price of the electricity is likely to cause the economic downturn.

Some scholars researched on the coordination mechanism of coal and electricity. The benefit sharing coordination mechanism for coal-electricity supply chain and government subsidy mechanism were established by using the game model and approaches [18-21], so as to analyze and discuss the practical significance, feasibility, and problems of coal-electricity integration, and the theoretical analytical framework for longitudinal transaction relationships was constructed $[14,22]$. Some scholars argued that the coordination problems of coal and electricity should be taken into account from the view of longitudinal arrangement of coal and electricity industrial chains [23]. Jiao et al. [24] suggested that the linkage mechanism for the price of coal-electricity is favorable to better outcome of the power enterprises by using the through game models.

The emergency reserve of coal is a typical issue of China. Liu and Zhu et al. $[25,26]$ have expounded the necessity of establishing national coal reserve system and proposed to establish countermeasures for a strategic coal reserve mechanism. Lv et al. [27, 28], from the aspects of measure of consumption, degree of self-sufficiency, terms of transportation, and economic strength and through cost-benefit analysis, have calculated the reserve scale in all provinces and regions. Sun et al. [29], through the fluctuation relation of the coal availability, have conducted a simulation study of the reserve size for a special project. Mou [30] used the generalized extreme-value approach to study coal demand shocks and to calculate the coal reserve scales against different coal demand shocks. And then some suggestions to guaranty China's coal supply security were put forward. However, the present analysis on the reasons of the tension between coalelectricity supplies is mainly based on qualitative analysis, but it is not able to probe into the in-depth study of the impacts of the price regulation on thermal coal and electricity and constraints of transportation on the coal-electricity supply.

As for the existing documents aiming at studying the countermeasures against the tension of coal-electricity supply, the status quo of double-track price regulations is mostly not taken into consideration in documents, and the countermeasure research on the mechanisms aiming at solving the tension of the coal-electricity supply is also lacked. According to the research on the coal emergency reserve, qualitative analysis is the primary approach, mainly focusing on the function of coal emergency reserve without touching upon the impacts of coal reserve on coal price and the decision making for the supply and demand of coal.

In order to alleviate the contradiction of the double-track regulations for coal price, Chinese National Development and Reform Commission announced at the end of the year 2012 that from January 1, 2013, the interventions of thermal coal temporary price are lifted; that is, the relevant regulations of price rise for the contracted thermal coal and the highest price fixing of the market transaction thermal coal in "Notice about regulating the price of thermal coal" [31] have been canceled. The price of the thermal coal shall be negotiated by supplying and purchasing parties, and a combination price 
pattern of the coal price will be realized. Thus, the impact of the combination price pattern of the coal price on the coalelectricity relationship in China needs to be studied further.

Recently, the game theory research has achieved significant progress, such as evolutionary games and coevolutionary games [32-41]. The game theory is always used to tackle the decision-making and coordination problem in supply chain [42-50]. Moreover, Szolnoki et al. [51, 52] studied the defense mechanisms of empathetic players and the evolution of fairness in the spatial ultimatum game.

Consequently, the double price regulations on the thermal coal and electricity and the uncertainties of the coalelectricity demands are taken into account in this paper, and in both situations whether the coal supply is constrained or not constrained by transportation, the game models are used to study the mechanism of the coal-electricity price conflicts under the conditions of the double price regulations and to analyze the impacts of the thermal coal price marketization on the coal-electricity price conflicts in China. Based on this, the peak shaving reserve mechanism of thermal coal is designed and the countermeasures against the difficult position of China's coal and electricity industries are discussed.

The innovation points of this paper are listed as follows. Firstly, the game model is established to analyze the double price regulations of the thermal coal and electricity, the constraint of transportation, and the impact of uncertainties of coal-electricity demands on the coal-electricity supply; accordingly, the reasons and mechanisms for the tension supply of thermal coal and electricity under the conditions of the coal-electricity price regulations are analyzed. Secondly, the impact of thermal coal price marketization on the coal-electricity supply is analyzed. Thirdly, according to the tension mechanism of the coal-electricity supply in China, the peak shaving reserve mechanism of thermal coal and model are constructed and the validity of the mechanism has been verified.

\section{Major Assumptions and Variable Declaration}

\subsection{Major Assumptions}

(1) A coal-electricity supply chain including one coal enterprise and one thermal power enterprise is taken as the object of study.

(2) For the convenience of study, when assuming that the output of the raw coal after washing is mainly clean coal and mixed coal, and the mixed coal is mainly the thermal coal to be sold to power enterprises for generating power, as coal belongs to staple products, the coal enterprises arrange production and supply according to the order of thermal coal whereas the demand of clean coal market is uncertain [53].

(3) The electricity demand is also uncertain.

(4) Owing to the distinctiveness of the thermal coal supply, the government gives an attention to the key thermal coal supply and the coal enterprises should assume the losses caused by shortage cost, for instance the loss of credibility when the thermal coal is short.

(5) As the electricity price is strictly regulated by the government if the research is conducted in a peak season and a slack season of coal demand, the electricity price remains unchanged, and under the conditions of regulation of thermal coal price, the contract price of the thermal coal is far lower than the market price of other coal (mainly the clean coal).

2.2. Variable Illustration. When assuming that the electricity price is $P_{e}$, it is strictly regulated by the government, the generating cost except coal is $C_{e}$, the generating quantity per ton coal is $\xi$, the shortage cost of electricity supply is $R_{e}$ including intangible costs such as the credit loss caused by short supply, the substitutable coefficient of mixed and clean coal is $\gamma$, namely, $\gamma$ tons of clean coal is generated if one ton of mixed coal is less produced, the production cost of mixed coal is $C_{c}$, and the clean coal cost is $C_{c} / \gamma$.

When assuming that the demand of power market in the peak season of coal demand is $D_{e} X$, among them $X$ is a random variable, its probability density function is $f(\cdot)$, the order quantity of thermal coal of power enterprises is $q_{e}$, and it is the decision variable of power enterprises, the output capacity of mixed coal of coal enterprises is $Q_{c}$, the negotiated price of thermal coal is $P_{c}$, the market price of clean coal is $P_{c c}$, the intended thermal coal supply quantity of coal enterprises is $q_{c}$, and it is the decision variable of coal enterprises, the order quantity of other coal (referring to clean coal in this paper) is $D_{c c} Y$, among them $Y$ is a random variable, and its probability density function is $g(\cdot)$, the inventory cost of coal is $H_{c}$, and shortage cost of thermal coal is $R_{c}$.

\section{Research on Game Models of Coal-Electricity in Boom Season of Coal Demand}

The supply decision of thermal coal of coal enterprises and order decision of thermal coal of power enterprises are studied under two situations when coal sales are constrained and not constrained by transportation during the boom season. And then the reason of the tension supply of coalelectricity in the peak season of coal demand is also analyzed.

3.1. Supply Decision of Thermal Coal without Constraint of Transportation. There exists a sequential game between power and coal enterprises. The game model is constructed and solved by using the backward induction. In the boom seasons of coal demand without constraint of transportation, the profit function of coal enterprise is as follows:

$$
\begin{aligned}
\pi_{c}^{N}= & P_{c} q_{c}+P_{c c} \min \left[D_{c c} Y, \gamma\left(Q_{c}-q_{c}\right)\right]-C_{c} Q_{c} \\
& -H_{c} \min \left[\gamma\left(Q_{c}-q_{c}\right)-D_{c c} Y, 0\right]-R_{c}\left(q_{e}-q_{c}\right),
\end{aligned}
$$

where the first item is the sales revenue of thermal coal, the second item is the sales revenue of clean coal, the third item is the production cost of coal, the fourth item is the storage 
cost of coal, and the fifth item is the shortage cost of thermal coal.

The expected profit function of coal enterprise is

$$
\begin{aligned}
E\left(\pi_{c}^{N}\right)= & P_{c} q_{c} \\
& +P_{c c}\left[\int_{-\infty}^{\gamma\left(Q_{c}-q_{c}\right) / D_{c c}} D_{c c} y g(y) d y\right. \\
& \left.+\int_{\gamma\left(Q_{c}-q_{c}\right) / D_{c c}}^{+\infty} \gamma\left(Q_{c}-q_{c}\right) g(y) d y\right] \\
& -C_{c} Q_{c}-H_{c} \int_{-\infty}^{\gamma\left(Q_{c}-q_{c}\right) / D_{c c}}\left[\gamma\left(Q_{c}-q_{c}\right)\right. \\
& -R_{c}\left(q_{e}-q_{c}\right) .
\end{aligned}
$$

Proposition 1. In the boom seasons of coal demand, the expected profit of coal enterprises $E\left(\pi_{c}\right)$ is a concave function of the intended supply quantity of thermal coal $q_{c}{ }^{N}$, and it conforms to the following formula:

$$
\int_{\gamma\left(Q_{c}-q_{c}{ }^{N}\right) / D_{c c}}^{+\infty} g(y) d y=\frac{\left(P_{c}+H_{c} \gamma+R_{c}\right)}{\left[\gamma\left(P_{c c}+H_{c}\right)\right]} .
$$

Proof. Since $d E \pi_{c}{ }^{N} / d q_{c}=P_{c}-P_{c c} \gamma \int_{\gamma\left(Q_{c}-q_{c}\right) / D_{c c}}^{+\infty} g(y) d y+$ $H_{c} \gamma \int_{-\infty}^{\gamma\left(Q_{c}-q_{c}\right) / D_{c c}} g(y) d y+R_{c}$,

$$
\frac{d^{2} E \pi_{c}{ }^{N}}{d q_{c}{ }^{2}}=-\frac{\left(P_{c c}+H_{c}\right) \gamma^{2}}{D_{c c}} g\left(\frac{\gamma\left(Q_{c}-q_{c}\right)}{D_{c c}}\right)<0 .
$$

So, $E\left(\pi_{c}{ }^{N}\right)$ is the concave function in $q_{c}$, and (3) may be derived if $d E \pi_{c}{ }^{N} / d q_{c}=0$.

On the left of (3) is a monotone increasing function about $q_{c}$. Therefore the intended supply quantity of thermal coal increases in the price and shortage cost of thermal coal and decreases in the market price and inventory cost of coal.

3.2. Decision Making of Thermal Coal Supply under the Constraint of Transportation. In fact, in the boom seasons of coal demand, the coal supply is usually constrained by transportation capacity. When supposing that in the boom seasons of coal demand, transportation capacity of coal is the bottleneck of coal supply, $T$ is transportation capacity of coal, and assuming that the transportation capacity of coal is not lower than the order quantity of thermal coal, the profit function of coal enterprises is

$$
\begin{aligned}
\pi_{c}{ }^{D}= & P_{c} q_{c}+P_{c c} \min \left[\left(T_{1}-q_{c}\right), D_{c c} Y\right] \\
& -C_{c}\left(q_{c}+\frac{\left(T-q_{c}\right)}{\gamma}\right) \\
& -H_{c} \min \left[\left(T-q_{c}\right)-D_{c c} Y, 0\right]-R_{c}\left(q_{e}-q_{c}\right),
\end{aligned}
$$

where the first item is the sales revenue of thermal coal, the second item is the sales revenue of clean coal, the third item is the production cost of coal, the fourth item is the storage cost of coal, and the fifth item is the shortage cost of thermal coal.

The expected profit function of coal enterprise is

$$
\begin{aligned}
E\left(\pi_{c}^{D}\right)= & P_{c} q_{c} \\
& +P_{c c}\left[\int_{-\infty}^{\left(T-q_{c}\right) / D_{c c}} D_{c c} y g(y) d y\right. \\
& \left.+\int_{\left(T-q_{c}\right) / D_{c c}}^{+\infty}\left(T-q_{c}\right) g(y) d y\right] \\
& -C_{c}\left(q_{c}+\frac{\left(T-q_{c}\right)}{\gamma}\right) \\
& -H_{c} \int_{-\infty}^{\left(T-q_{c}\right) / D_{c c}}\left[T-q_{c}-D_{c c} y\right] g(y) d y \\
& -R_{c}\left(q_{e}-q_{c}\right) .
\end{aligned}
$$

Proposition 2. In the boom seasons of coal demand and under the constraint of transportation, the expected profit of coal enterprise $E\left(\pi_{c}^{D}\right)$ is the function of the intended supply quantity of thermal coal and the intended supply quantity of thermal coal $q_{c}{ }^{D}$ conforms to the following formula:

$$
\begin{aligned}
\int_{\left(T-q_{c}{ }^{D}\right) / D_{c c}}^{+\infty} g(y) d y & \\
= & \frac{\left[\gamma\left(P_{c}+R_{c}+H_{c}\right)+C_{c}(1-\gamma)\right]}{\left[\gamma\left(P_{c c}+H_{c}\right)\right]} .
\end{aligned}
$$

Proof. Since $d E \pi_{c} / d q_{c}=P_{c}-P_{c c} \int_{\left[T-q_{c}\right] / D_{c c}}^{+\infty} g(y) d y-C_{c}(1-$ $1 / \gamma)+H_{c} \int_{-\infty}^{\left[T-q_{c}\right] / D_{c c}} g(y) d y+R_{c}$

$$
\frac{d^{2} E \pi_{c}}{d q_{c}^{2}}=-\frac{\left(P_{c c}+H_{c}\right)}{D_{c c}} g\left(\frac{\left(T-q_{c}\right)}{D_{c c}}\right)<0 .
$$

So, $E\left(\pi_{c}\right)$ is the concave function of $q_{c}{ }^{D}$, and if $d E \pi_{c} / d q_{c}=0$, (7) may be gained.

On the left of (7) is a monotonous increasing function about $q_{c}$. Therefore the intended supply quantity of thermal coal increases in the price and shortage cost of thermal coal and decreases in the market price and the inventory cost of coal. It is similar to the conclusions without transportation constraint.

3.3. Decision Making of Ordering Thermal Coal by Power Enterprise in Boom Seasons of Coal Demand. In boom seasons of coal demand, power enterprises have to make decisions of the ordering quantity of thermal coal. The profit function of power enterprises is

$$
\begin{aligned}
\pi_{e}= & \left(P_{e}-C_{e}\right) \min \left(D_{e} X, \xi q_{e}\right) \\
& -P_{c} q_{e}-R_{e} \max \left(D_{e} X-\xi q_{e}, 0\right),
\end{aligned}
$$


where the first item is the difference of the sales revenue of electricity with the generating cost except the thermal coal, the second item is the purchase cost of thermal coal, and the third item is the shortage cost of power.

According to the backward induction, the power enterprises make decisions of the ordering quantity of thermal coal. The decision-making model is

$$
\begin{aligned}
\max E \pi_{e}= & \left(P_{e}-C_{e}\right) \\
& \times\left[\int_{-\infty}^{\xi q_{e} / D_{e}} D_{e} x f(x) d x\right. \\
& \left.\quad+\int_{\xi q_{e} / D_{e}}^{+\infty} \xi q_{e} f(x) d x\right]-P_{c} q_{e} \\
& -R_{e} \int_{\xi q_{e} / D_{e}}^{+\infty}\left(D_{e} x-\xi q_{e}\right) f(x) d x
\end{aligned}
$$

Proposition 3. In boom seasons of coal demand, the expected profit of power enterprises $E \pi_{e}$ is a concave function of the ordering quantity of thermal coal $q_{e}$. Under this situation, the ordering quantity of power enterprises satisfied the following model:

$$
\int_{\xi q_{e} / D_{e}}^{+\infty} f(x) d x=\frac{P_{c}}{\left[\left(P_{e}+R_{e}-C_{e}\right) \xi\right]} .
$$

Proof. Since

$$
\begin{gathered}
\frac{d E \pi_{e}}{d q_{c}}=\xi\left(P_{e}+R_{e}-C_{e}\right) \int_{\xi q_{e} / D_{e}}^{+\infty} f(x) d x-P_{c} \\
\frac{d^{2} E \pi_{e}}{d q_{c}^{2}}=-\frac{\left(P_{e}+R_{e}-C_{e}\right) \xi^{2}}{D_{e}} f\left(\frac{\xi q_{e}}{D_{e}}\right)<0 .
\end{gathered}
$$

So, $E \pi_{e}$ is a concave function of $q_{e}$ and there exists the optimal ordering quantity of thermal coal by power enterprises, and (11) is gained if $d E \pi_{e} / d q_{e}=0$.

It can be seen from (11) that the ordering quantity of thermal coal by power enterprises deceases with the increase of the price of thermal coal. Under this decision making, the actual supply quantity of thermal coal is $\min \left(q_{e}, q_{c}\right)$, and then the probability of shortage proportion of power supply is

$$
\begin{aligned}
P\{\xi \min & \left.\left(q_{e}, q_{c}\right)<(1-\beta) D_{e} X\right\} \\
& =\int_{\xi \min \left(q_{e}, q_{c}\right) /\left[(1-\beta) D_{e}\right]}^{+\infty} f(x) d x .
\end{aligned}
$$

\section{The Peak Shaving Reserve Mechanism of Thermal Coal}

It is a major step to realize the marketization of coal through lifting the temporary intervention in thermal coal price. However, owing to the particularity of electrical energy, the constant rise of power price will result in series of serious consequences such as economic slowdown [17]. Therefore, in the short term, it is hard for the government to completely ease restrictions on the power price. In the situation of the price rise of thermal coal and power price still regulated by the government, the enthusiasm of power enterprises to order thermal coal is further discouraged and the power shortage may be further aggravated. How to solve the price inversion problem after the launch of marketization pattern of the thermal coal price has become an urgent issue.

In order to solve the more prominent conflict of price inversion of electricity and coal caused by marketization pattern of the thermal coal price, a peak shaving reserve mechanism is put forward in this study; firstly, power enterprises and relevant departments should carry out the coal reserve in slack seasons of coal demand, and secondly, in the boom seasons of coal demand, if the price of thermal coal is too high and there is a tension of thermal coal supply, the coal reserve may be put into use to adjust the peak demand of thermal coal so that the coal price in boom seasons may be reduced.

The market price of clean coal is $P_{c c}$; it is determined by the market demand. Assuming that

$$
P_{c c}=p\left(\frac{D_{e}}{\xi}+\frac{D_{c c}}{\gamma}\right)=a\left(\frac{D_{e}}{\xi}+\frac{D_{c c}}{\gamma}\right)+b,
$$

$\Delta q$ denotes the peak shaving reserve quantity of thermal coal and $P_{c 2}$ denotes the purchase price of the reserved coal $\left(P_{c 2}<P_{c}\right)$. Under the condition of the peak shaving reserve mechanism, if the ordering quantity of thermal coal is $\widetilde{q}_{c}$, the price of clean coal is

$$
\widetilde{P}_{c c}=a\left(\frac{D_{e}}{\xi}+\frac{D_{c c}}{\gamma}-\Delta q\right)+b .
$$

Through a comparison of (14) and (15), it can be seen that under the condition of the peak shaving reserve mechanism, the expected demand of coal is reduced and the market price of coal lowered under the influence of the peak shaving reserve mechanism.

In a similar way to Proposition 1, under the condition of the peak shaving reserve mechanism without the constraint of transportation capacity, the intended supply quantity of thermal coal from the coal enterprises may satisfy the following model:

$$
\int_{\left[\gamma\left(\mathrm{Q}_{c}-\widetilde{q}_{c}^{N}\right)\right] / D_{c c}}^{+\infty} g(y) d y=\frac{\left[\widetilde{P}_{c}+H_{c} \gamma+R_{c}\right]}{\left[\gamma\left(\widetilde{P}_{c c}+H_{c}\right)\right]} .
$$

In a similar way with Proposition 2, under the condition of the peak shaving reserve mechanism with the constraint of transportation capacity, the intended supply quantity of thermal coal from the coal enterprises may satisfy the following model:

$$
\int_{\left[T-\widetilde{q}_{c}^{D}\right] / D_{c c}}^{+\infty} g(y) d y=\frac{\left[\gamma\left(\widetilde{P}_{c}+R_{c}+H_{c}\right)+C_{c}(1-\gamma)\right]}{\left[\gamma\left(\widetilde{P}_{c c}+H_{c}\right)\right]} .
$$


In boom seasons of coal demand, the power enterprises have to make decisions of the ordering quantity of thermal coal. The profit function of power enterprises is

$$
\begin{aligned}
\tilde{\pi}_{e}= & \left(P_{e}-C_{e}\right) \min \left[D_{e} X, \xi\left(\tilde{q}_{e}+\Delta q\right)\right] \\
& -\widetilde{P}_{c} \widetilde{q}_{e 1}-\left(P_{c 2}+H_{c}\right) \Delta q \\
& -R_{e} \max \left[D_{e} X-\xi\left(\tilde{q}_{e}+\Delta q\right), 0\right],
\end{aligned}
$$

where the first item is the balance of sales revenue of power with the generating cost except the thermal coal. The second item is the purchase cost of thermal coal in boom seasons of coal demand. The third item is the purchase and reserve cost of the reserved thermal coal. The fourth item is the shortage cost of power.

The expected profit of power enterprises is

$$
\begin{aligned}
E \tilde{\pi}_{e}= & \left(P_{e}-C_{e}\right) \\
& \times\left[\int_{-\infty}^{\xi\left(\widetilde{q}_{e}+\Delta q\right) / D_{e}} D_{e} x f(x) d x\right. \\
& \left.\quad+\int_{\xi\left(\widetilde{q}_{e}+\Delta q\right) / D_{e}}^{+\infty} \xi\left(\widetilde{q}_{e}+\Delta q\right) f(x) d x\right]-\widetilde{P}_{c} \widetilde{q}_{e} \\
& -\left(P_{c 2}+H_{c}\right) \Delta q \\
& -R_{e} \int_{\xi\left(\widetilde{q}_{e}+\Delta q\right) / D_{e}}^{+\infty}\left(D_{e} x-\xi\left(\widetilde{q}_{e}+\Delta q\right)\right) f(x) d x .
\end{aligned}
$$

Proposition 4. Under the condition of the peak shaving reserve mechanism, the expected profit $E \pi_{e}$ of power enterprises in the boom seasons of coal demand is concave in $q_{e}$. In this situation, the ordering quantity of power enterprises may satisfy the following model:

$$
\int_{\xi\left(\widetilde{q}_{e}+\Delta q\right) / D_{e}}^{+\infty} f(x) d x=\frac{\widetilde{P}_{c}}{\left[\xi\left(P_{e}+R_{e}-C_{e}\right)\right]} .
$$

Under the condition of the peak shaving reserve mechanism, the probability of shortage proportion of power supply is

$$
\begin{aligned}
P\{\xi[ & \left.\left.\min \left(q_{e}, q_{c}\right)+\Delta q\right]<(1-\beta) D_{e} X\right\} \\
& =\int_{\xi\left[\min \left(q_{e}, q_{c}\right)+\Delta q\right] /\left[(1-\beta) D_{e}\right]}^{+\infty} f(x) d x .
\end{aligned}
$$

\section{Numerical Analysis}

The parameters are set as follows $P_{e}=4000$ (Yuan $/ 10^{4} \mathrm{kw}$ $\mathrm{h}$ ), $R_{e}=400$ (Yuan $/ 10^{4} \mathrm{kw}-\mathrm{h}$ ), $C_{e}=1800$ (Yuan $/ 10^{4} \mathrm{kw}-\mathrm{h}$ ), $\xi=0.33$ (Yuan $/ 10^{4} \mathrm{kw}-\mathrm{h}$ ), $C_{c}=300$ (Yuan $/ 10^{4} \mathrm{kw}-\mathrm{h}$ ), and $\gamma=$ 0.60 . The random variable of demand fluctuation of power market $X$ is subject to uniform distribution $U(1-m, 1+m)$, $0<m<1$, and the random variable of demand fluctuation of clean coal market $Y$ is subject to uniform distribution $U(1-$ $n, 1+n), 0<n<1$. In boom seasons of coal demand, let $D_{e}=50\left(10^{8} \mathrm{kw}-\mathrm{h}\right) ; D_{c c}=80$ (10 ${ }^{4}$ tons $), Q_{c}=260$ (10 ${ }^{4}$ tons $) ;$ $H_{c}=20$ (Yuan/ton), $R_{c}=100$ (Yuan/ton).
The price coefficients of clean coal market are $a=3.2$, $b=200$, and $\mu=0.53$. The purchase cost of coal under peak shaving reserve is 500 Yuan/ton, but it should increase to 520 Yuan/ton plus the storage cost. Under the conditions of the price regulations, the marketization pattern of the thermal coal price, the peak shaving reserve mechanism with or without the constraint of transportation, the thermal coal supply, the ordering decision making, and the probabilities of short supply of power are shown in Tables 1-3, respectively.

Under the conditions of the price regulations of thermal coal and in boom seasons of coal demand, the price rise of thermal coal is regulated; it may not exceed 5\% usually, and from Tables 1, 2, and 3, the price of thermal coal at present is 525 Yuan/ton. Thus, from Tables 1, 2, and 3 it can be seen that.

(1) Under the conditions of the price regulations of thermal coal and in boom season of coal demand, there exists a difference between the thermal coal price and the market price of coal; thus, the enthusiasm of the coal enterprises to supply the thermal coal should be reduced, and the intended supply quantity of the coal enterprises should be also reduced. Therefore, the coal enterprises always become the major reason for short supply of power, and sometimes the electricity enterprises become the reason for short power supply because of low enthusiasm for ordering thermal coal.

(2) Under the marketization pattern of thermal coal price and in the boom seasons of coal demand, the price of thermal coal increases dramatically, and the intended supply quantity of thermal coal by coal enterprises increases significantly. But due to the price inversion of electricity and coal, the enthusiasm for ordering thermal coal by the power enterprises decreases evidently. From this, the power enterprises become the major reason for short supply of power.

(3) The enthusiasm of coal enterprises to supply the thermal coal is clearly lower if the coal supply is constrained by transportation capacity. Under the situation of constrained transportation capacity, the risk of power supply may increases notably.

(4) The uncertainties of power market demand impact the order quantity of thermal coal by power enterprises and the probability of the power shortage. It is likely to be less than the intended quantity of coal enterprises. Thus, the power enterprises may become the major reason for short supply of power.

(5) The uncertainties of the demand of coal market impose great influence upon the intended supply quantity of thermal coal by coal enterprises. Along with more uncertainties of the demand of coal market, coal enterprises have to shoulder higher market risks. In order to avoid the risks, the coal enterprises tend to meet the relatively stable orders in the market.

(6) Under the condition of the peak shaving reserve mechanism of thermal coal, the price of coal market deceases. Therefore, the enthusiasm of power enterprises to order thermal coal increases. Along with 
TABLE 1: Decision and results in boom seasons of coal demand under the conditions of double price regulation by the government.

\begin{tabular}{|c|c|c|c|c|c|c|c|c|c|}
\hline & & $m$ & $n$ & $P\left(Y_{11 a n} /\right.$ ton $)$ & a $\left(10^{4}\right.$ tons $)$ & $a \quad\left(10^{4}\right.$ tons $)$ & Probabil & ty of power sho & tage (\%) \\
\hline & & $m$ & $n$ & $r_{c}($ ruan/ton $)$ & (OHS) & (10 lons) & $10 \%$ shortage & $20 \%$ shortage & $30 \%$ shortage \\
\hline & & & 0.1 & & 138 & 145 & 46 & 15 & 0 \\
\hline & & 0.2 & 0.2 & 525 & 150 & 145 & 35 & 1 & 0 \\
\hline & $\begin{array}{l}\text { Without } \\
\text { transport }\end{array}$ & & 0.3 & & 162 & 145 & 35 & 1 & 0 \\
\hline & constraints & 0.1 & & & 150 & 148 & 7 & 0 & 0 \\
\hline Without & & 0.2 & 0.2 & 525 & 150 & 145 & 35 & 1 & 0 \\
\hline Coordination & & 0.3 & & & 150 & 141 & 44 & 22 & 0 \\
\hline Contract & & & 0.1 & & 124 & 145 & 73 & 44 & 8 \\
\hline & & 0.2 & 0.2 & 525 & 128 & 145 & 66 & 36 & 0 \\
\hline & Transport & & 0.3 & & 132 & 145 & 58 & 28 & 0 \\
\hline & constraints & 0.1 & & & 128 & 148 & 81 & 22 & 0 \\
\hline & & 0.2 & 0.2 & 525 & 128 & 145 & 66 & 36 & 0 \\
\hline & & 0.3 & & & 128 & 141 & 60 & 41 & 16 \\
\hline
\end{tabular}

TABLE 2: Decision and results in boom seasons of coal demand under marketization pattern of the thermal coal price.

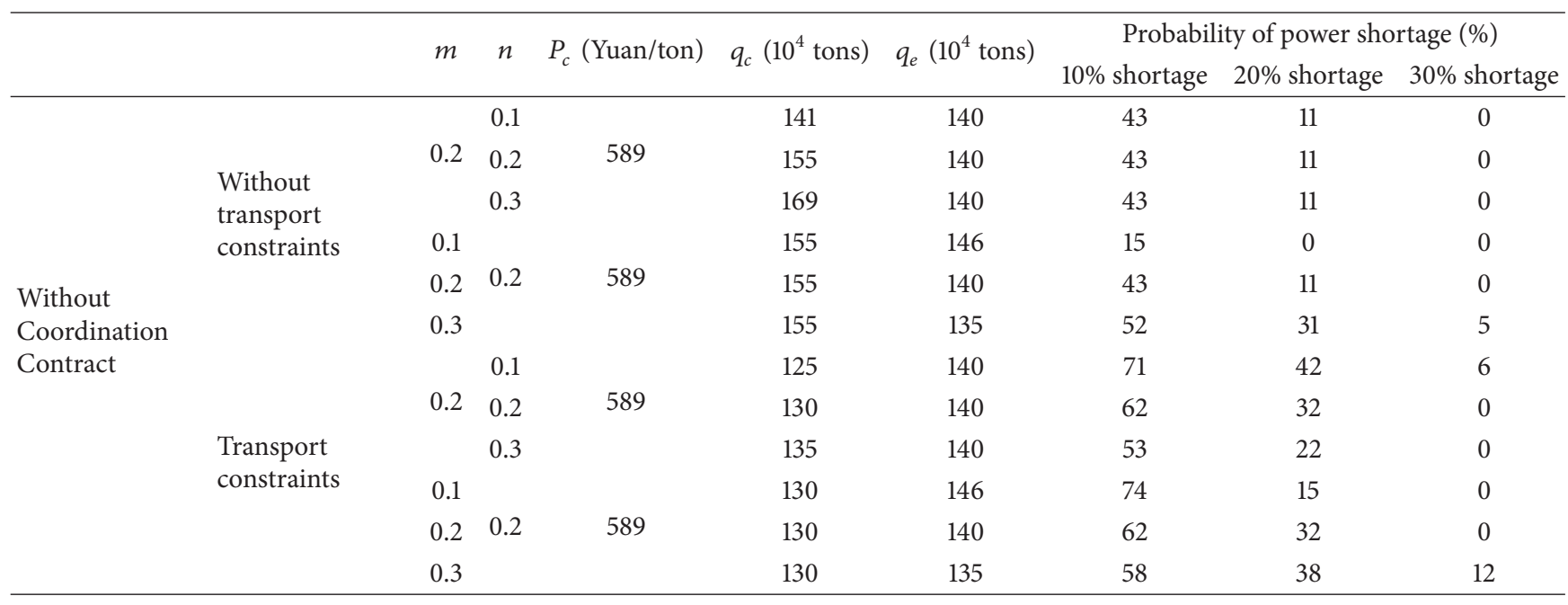

TABLE 3: Decision and results in boom seasons of coal demand under the condition of peak shaving reserve mechanism $(\Delta q=20)$.

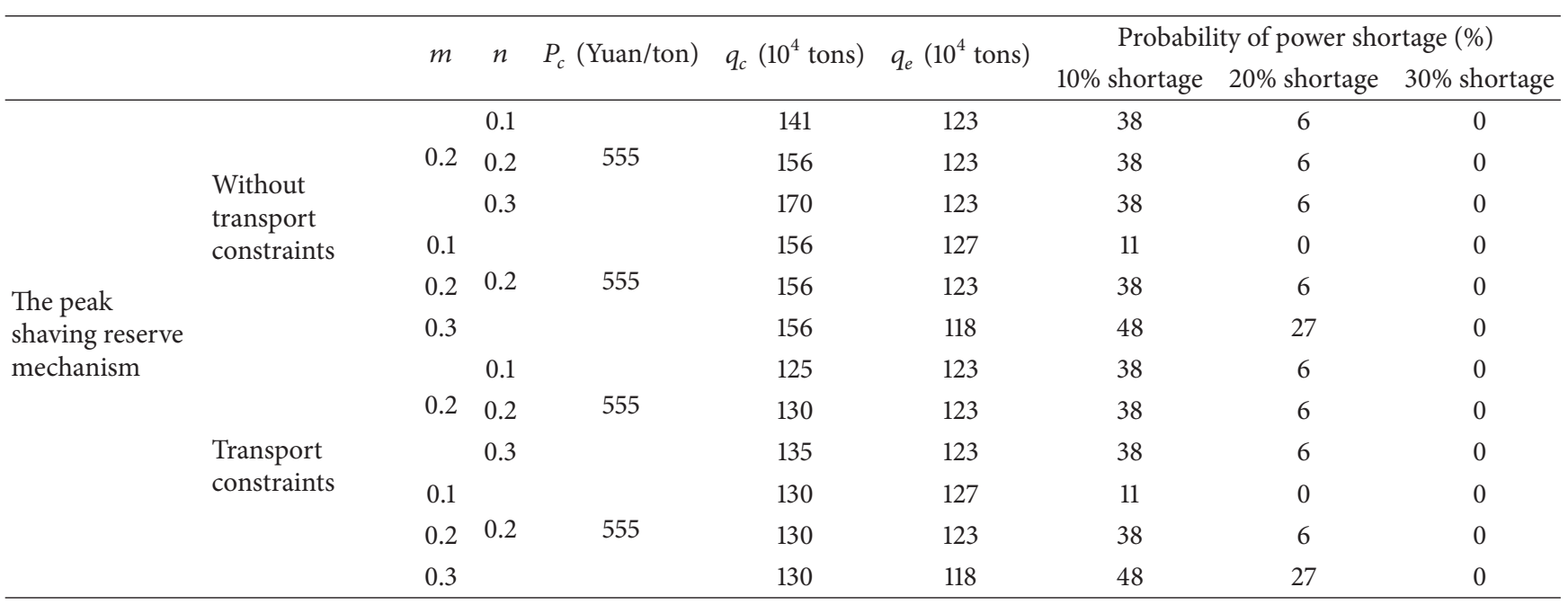


the regulating effect of thermal coal reserve, the probability of short power supply decreases dramatically; it proves that there is an obvious effect of shaving peak reserve mechanism of thermal coal.

\section{Results}

6.1. The Mechanism of Tension of Electricity Supply and Coal Supply in Boom Seasons of Coal Demand under the Conditions of Price Regulations of Thermal Coal. Under the conditions of the double price regulations, the thermal coal price is regulated by the government. In the boom seasons of coal demand, the rise of price is limited to the level far lower than that in the market price. Based on the above analysis, the mechanism of the tension of coal-electricity supply chain is as follows.

Result 1. In the boom seasons of coal demand, the price regulation of thermal coal discourages the enthusiasm of the coal enterprises to supply thermal coal; it leads to a relatively low level of intended supply quantity of thermal coal.

From (3) and (7), it can be seen that in boom seasons of coal demand, no matter whether coal supply is constrained by transportation, the intended supply quantity of the coal enterprises increases in the negotiated price $P_{c}$ of thermal coal. Under the conditions of price regulation of thermal coal and in boom seasons of coal demand, the thermal coal price is lower than the market price of the same quality; thus, the enthusiasm of the coal enterprises to supply thermal coal may be discouraged and it leads to the fairly low level of intended supply quantity of thermal coal.

Result 2. In boom seasons of coal demand, the transportation capacity constrains the enthusiasm of the thermal coal supply by the coal enterprises, and it leads to less intended supply quantity of thermal coal.

When subtracting (3) from (7), the following formula is gained:

$$
\begin{gathered}
\int_{\gamma\left(Q_{c}-q_{c}^{N}\right) / D_{c c}}^{+\infty} g(y) d y-\int_{\left[T-q_{c}^{D}\right] / D_{c c}}^{+\infty} g(y) d y \\
=\frac{(1-\gamma)\left(P_{c}+R_{c}-C_{c}\right)}{\left[\gamma\left(P_{c c}+H_{c}\right)\right]}>0 .
\end{gathered}
$$

In other words, in boom seasons of coal demand, when coal supply is constrained by transportation, the intended supply quantity is lower than that without constraint by transportation; namely, the constraint of coal transportation discourages the enthusiasm of the coal enterprises to supply thermal coal.

Result 3. In boom seasons of coal demand, because of the strict regulation of electricity price, the longitudinal dualtrack price system is formed; it leads to the price inversion of coal and electricity. Consequently, the enthusiasm of power enterprises to order thermal coal is discouraged.

From (11), it can be seen that the ordering quantity of thermal coal by the power enterprises decreases in the thermal coal price. In boom seasons of coal demand, as the price of electricity is strictly regulated, in the process of the gradual marketization of the of thermal coal price, there exists the price inversion of electricity and coal; it leads to the lower enthusiasm of the power enterprises to order thermal coal and generate power.

6.2. Impact of Analysis on the Coal-Electricity Supply under Marketization System of Thermal Coal Price. Since the launching of marketization pattern of thermal coal price, the government will no longer intervene in the thermal coal price and the price is determined by the market only. As the sales of thermal coal take up more than a half of the whole coal sales, coal enterprises may give certain price discount to power enterprises. In this case, the thermal coal price will fluctuate with the coal market after launching marketization pattern of thermal coal price. In the boom seasons of coal demand, although there is price discount, the price is not lower than that under the price regulation.

The thermal coal price in boom seasons of coal demand is $\widetilde{P}_{c}=\mu \widetilde{P}_{c c}$, where, the coefficient $\mu$ is relative to substitutable ratio $\gamma$ of mixed and clean coal and to the negotiation ability of power enterprises; namely, the price discount rate of thermal coal is included.

Result 4. Under the marketization pattern of thermal coal price and in boom seasons of coal demand, the enthusiasm of coal enterprises to supply thermal coal increases and the intended supply quantity of thermal coal by coal enterprises is enhanced.

From (3) and (7), it can be seen that in boom seasons of coal demand, no matter whether coal supply is constrained by transportation, the intended supply quantity of coal enterprises increases with the increase of the negotiated price $P_{c}$ of thermal coal. Under the marketization pattern of thermal coal price, the thermal coal price usually is higher than that under price regulation, the enthusiasm of the coal enterprises to supply thermal coal may increase, and it may lead to the high level of intended supply quantity of thermal coal.

Result 5. Under the marketization pattern of thermal coal price, the price inversion caused by the longitudinal dualtrack price system becomes more prominent and the enthusiasm of power enterprises to order thermal coal is further discouraged.

From (11), it can be seen that in boom seasons of coal demand and under the marketization pattern of thermal coal price, the thermal coal price is usually higher than that under price regulation. In this case, the ordering quantity of power enterprises may be reduced. In other words, under the marketization pattern of thermal coal price, as the power price is strictly regulated by the government, the conflict of price inversion turns more prominent. Therefore, the enthusiasm of power enterprises to order thermal coal and generating power is even lower.

Due to the recent impact of the international economic crisis, the domestic coal market remains weak and the coal price is constantly declining. Thus, the price of coal market is fairly close to that under the price regulation, and it indicates 
that the impact of the marketization pattern of thermal coal price is not manifested. Under the improved macroeconomic situations, the market demand and coal price are bound to increase gradually, the seasonal conflicts between the supply and demand of coal are bound to reoccur, and the coal price is bound to pick up in a steady way.

\subsection{Effect Analysis of Peak Shaving Reserve Mechanism}

Result 6 . Under the peak shaving reserve mechanism and in the peak season of coal demand, if power enterprises use the reserved coal, the market price of coal will decrease.

Through a comparison of (14) and (15), it can be seen that under the peak shaving reserve mechanism the expected demand of coal reduces and the price of coal market decreases; namely, $\widetilde{P}_{c c}<P_{c c}$. So $\widetilde{P}_{c}=\mu \widetilde{P}_{c c}<P_{c}=\mu P_{c c}$.

Result 7. Under the peak shaving reserve mechanism and in the boom seasons of coal demand, the intended supply quantity of thermal coal from the coal enterprises is evidently improved. Through a comparison of (3) and (15), the intended supply of thermal coal by coal enterprises without transport constraints is compared because of $\widetilde{P}_{c c}<P_{c c}$ as follows:

$$
\begin{gathered}
\int_{\gamma\left(\mathrm{Q}_{c}-\widetilde{q}_{c}^{N}\right) / D_{c c}}^{+\infty} g(y) d y-\int_{\gamma\left(\mathrm{Q}_{c}-q_{c}^{N}\right) / D_{c c}}^{+\infty} g(y) d y \\
=\frac{\left[(\gamma-\mu) H_{c}+R_{c}\right]}{\left[\gamma\left(\widetilde{P}_{c c}+H_{c}\right)\right]}-\frac{\left[(\gamma-\mu) H_{c}+R_{c}\right]}{\left[\gamma\left(P_{c c}+H_{c}\right)\right]}>0 .
\end{gathered}
$$

Therefore, $\widetilde{q}_{c}^{N}>q_{c}{ }^{N}$.

Through a comparison of (7) and (17), the intended supply of thermal coal by coal enterprises with transport constraints is compared as follows:

$$
\begin{gathered}
\int_{\left(T-\widetilde{q}_{c}^{D}\right) / D_{c c}}^{+\infty} g(y) d y-\int_{\left(T-q_{c}{ }^{D}\right) / D_{c c}}^{+\infty} g(y) d y \\
=\frac{\left[\gamma\left(R_{c}+(1-\mu) H_{c}\right)+C_{c}(1-\gamma)\right]}{\left[\gamma\left(\widetilde{P}_{c c}+H_{c}\right)\right]} \\
-\frac{\left[\gamma\left(R_{c}+(1-\mu) H_{c}\right)+C_{c}(1-\gamma)\right]}{\gamma\left(P_{c c}+H_{c}\right)}>0 .
\end{gathered}
$$

Therefore, $\tilde{q}_{c}^{D}>q_{c}^{D}$.

Result 8. Under the peak shaving reserve mechanism, the enthusiasm of the power enterprises to generate power may be increased and the risks of short power supply are lowered.

Through a comparison of (11) and (20) and because of $\widetilde{P}_{c}<P_{c}$,

$$
\begin{aligned}
\int_{\xi q_{e} / D_{e}}^{+\infty} f(x) d x-\int_{\xi\left(\widetilde{q}_{e}+\Delta q\right) / D_{e}}^{+\infty} f(x) d x \\
\quad=\frac{P_{c}}{\left[\xi\left(P_{e}+R_{e}-C_{e}\right)\right]}-\frac{\widetilde{P}_{c}}{\left[\xi\left(P_{e}+R_{e}-C_{e}\right)\right]}>0
\end{aligned}
$$

and then $\tilde{q}_{e}+\Delta q>q_{e}$.

\section{Discussions and Conclusions}

The reason of conflict between coal and electricity is not only the low enthusiasm of coal enterprises to supply thermal coal under the conditions of the price regulation of thermal coal but also the low enthusiasm of electricity enterprises to order thermal coal under the condition of electricity price regulation. In order to solve the conflict between coal and electricity, the transverse price double track caused by coal price regulation and the longitudinal price double track caused by electricity price regulation should be eased.

The advice of coal-electricity integration $[14,22]$ cannot solve the problem of the longitudinal price double track caused by electricity price regulation. And coal-electricity integration is not easy to carry out widely. The linkage mechanism for the coal-electricity price [24] may ease the longitudinal price double track caused by electricity price regulation. But the problem of the transverse price double track caused by coal price regulation may be not solved. Also the electricity price increase has an adverse influence on the total output, Gross Domestic Product (GDP), and the Consumer Price Index (CPI), and electricity price increases have a contractionary effect on economic development [17]. Under the situation of thermal coal price marketization, the problem of transverse price double track caused by coal price regulation may be eased, but the problem of longitudinal price double track caused by electricity price regulation is even more serious, and the risk of coal-electricity conflict may be greater.

Under the situation of thermal coal price marketization, the policy of peak shaving reserve of thermal coal can adjust the ordering quantity of thermal coal and reduce the price of coal market. It can ease the problem of transverse price double track caused by coal price regulation and the problem of longitudinal price double track caused by electricity price regulation. And the policy of peak shaving reserve of thermal coal may also alleviate the pressure of coal transportation in boom seasons of coal demand. Therefore, the probability of power shortage reduces significantly; at the same time it may also ease the conflicts between coal and electricity. Thus, it is an effective policy to solve the conflict problem of coalelectricity in China.

The major conclusions are illustrated as follows.

(1) In the boom seasons of coal demand, the price regulation of thermal coal discourages the initiatives of the coal enterprises to supply thermal coal; it results in a relatively low intended quantity of coal supply. The longitudinal dual-track price system of thermal coal is brought into being because of the strict regulation of power price, it leads to the price inversion of electricity and coal, and furthermore the initiative of the power enterprises to order thermal coal is discouraged. Both coal enterprises and power enterprises are likely to be the major reason of short power supply.

(2) In the boom seasons of coal demand, the constraint of the transportation capacity of coal discourages the initiatives of coal enterprises to supply thermal coal, 
and it leads to less intended quantity of thermal coal supply.

(3) Under the marketization pattern of thermal coal price and in the boom seasons of coal demand, the initiatives of the coal enterprises to supply thermal coal increase. But, the dual-track price system of electricity and coal leads to a more prominent conflict of the price inversion of coal and electricity, and the enthusiasm of the power enterprises to order thermal coal is further discouraged.

(4) Under the mechanism of peak shaving reserve and in the boom seasons of coal demand, power enterprises will put the reserved coal into use. Therefore, the price of coal market may be reduced and the intended quantity of the thermal coal supply from the coal enterprises may be increased largely. The ordering quantity of thermal coal from the power enterprises may be correspondingly enhanced. Under the mechanism of peak shaving reserve, the risk of short power supply is sharply reduced.

(5) The ordering quantity of thermal coal from the power enterprises decreases in the uncertainties of the power market demand; the more the uncertainties of the market demand are, the more intended supply quantity of thermal coal and the enthusiasm for supplying thermal coal the coal enterprises will be.

One of the policy implications is that the price regulation policy on the thermal coal and electricity causes the conflict between coal and electricity. The price regulation of thermal coal decreases the intended supply quantity of the coal enterprises and the strict regulation of power price discourages the initiatives of the power enterprises to order thermal coal. Under the marketization policy of thermal coal price, the dual-track price system of coal-electricity leads to a more prominent conflict of the price inversion of coal and electricity and the enthusiasm of the power enterprises to order thermal coal is further discouraged.

Chinese government should make policy to encourage the thermal coal peak shaving reserve, so that the price of coal market reduces accordingly, the intended quantity of the thermal coal supply from the coal enterprises increases largely, and the ordering quantity of thermal coal from the power enterprises is correspondingly enhanced. Under the mechanism of peak shaving reserve, the risk of short power supply is sharply reduced, and the conflict between coal and electricity may be solved effectively.

Chinese government should support the construction of peak shaving reserve warehouses of thermal coal in technology, capital, policy, and so forth. At present, the demand of coal market is not prosperous and the coal price is rather on the low side. Thus, there is an opportunity to build the peak shaving reserve warehouses of thermal coal and the study work of peak shaving reserve of thermal coal should be carried out.

\section{Acknowledgment}

This research was supported by the National Natural Science Foundation of China (Grant no. 71201164).

\section{References}

[1] Y. Sun and H. Zhang, "A study of China's coal pricing mechanism under the financial crisis," Reformation \& Strategy, vol. 26, no. 6, pp. 34-35, 2010 (Chinese).

[2] Z. Yu and X. Kong, "The formation mechanism of tense atmosphere in coal-electricity relationships in the policies conflict aspects," China Industrial Economics, no. 4, pp. 46-57, 2010 (Chinese).

[3] L. Shen, T.-M. Gao, and X. Cheng, "China's coal policy since 1979: a brief overview," Energy Policy, vol. 40, no. 1, pp. 274-281, 2012.

[4] P. Arocena, I. Contín, and E. Huerta, "Price regulation in the Spanish energy sectors: who benefits?” Energy Policy, vol. 30, no. 10, pp. 885-895, 2002.

[5] A. Ciarreta and M. P. Espinosa, "The impact of regulation on pricing behavior in the Spanish electricity market (2002-2005)," Energy Economics, vol. 34, no. 6, pp. 2039-2045, 2012.

[6] G. Coco and C. de Vincenti, "Can price regulation increase costefficiency?" Research in Economics, vol. 58, no. 4, pp. 303-317, 2004.

[7] D. L. Weisman, "Price regulation and quality," Information Economics and Policy, vol. 17, no. 2, pp. 165-174, 2005.

[8] T. A. Johnsen and O. J. Olsen, "Regulated and unregulated Nordic retail prices," Energy Policy, vol. 39, no. 6, pp. 3337-3345, 2011.

[9] Z. X. Wang, "Application of grey linear control theory for price regulation in China's real estate market," Grey Linear Control Theory, vol. 42, no. 3, pp. 413-422, 2013.

[10] G. Guthrie, "Regulated prices and real options," Telecommunications Policy, vol. 36, no. 8, pp. 650-663, 2012.

[11] D. A. Galbi, "Regulating prices for shifting between service providers," Information Economics and Policy, vol. 13, no. 4, pp. 393-410, 2001.

[12] C. Chen and W. Peng, "Review and Evaluation on Coalelectricity Linkage Policy in China," Journal of China University of Geosciences (Social Sciences Edition), vol. 9, no. 1, pp. 45-49, 2009 (Chinese).

[13] B. Wang, "An imbalanced development of coal and electricity industries in China," Energy Policy, vol. 35, no. 10, pp. 49594968, 2007.

[14] X. Zhao, T. P. Lyon, F. Wang, and C. Song, "Why do electricity utilities cooperate with coal suppliers? A theoretical and empirical analysis from China," Energy Policy, vol. 46, no. 1, pp. 520529,2012

[15] C. Qu and Y. Qin, "A study of coal-electricity relationship based on bargaining game," Journal of Shandong University (Social Sciences Edition), no. 6, pp. 1-13, 2010 (Chinese).

[16] J. Chen, J. Lv, and W. Yao, "Risk assessment and control of thermal coal logistics under supply chain link division," China Safety Science Journal, vol. 21, no. 2, pp. 159-164, 2011 (Chinese).

[17] Y. X. He, S. L. Zhang, L. Y. Yang, Y. J. Wang, and J. Wang, "Economic analysis of coal price-electricity price adjustment in China based on the CGE model," Energy Policy, vol. 38, no. 11, pp. 6629-6637, 2010. 
[18] X. Zhao and J. Qi, "Distribution of cooperation benefits under different supply chains: the case of coal and electric power enterprises," Chinese Journal of Management Science, vol. 15, no. 4, pp. 70-76, 2007 (Chinese).

[19] X. Zhao and J. Qi, "Regulation model of supply chain cooperative conflict: the case of coal and electric power enterprises," Chinese Journal of Management Science, vol. 16, no. 4, pp. 96103, 2008 (Chinese).

[20] L. Gui, Z. Gu, Y. Qiao et al., "Designing earnings coordination system for Chinese coal-electricity enterprises based on government regulation," China Soft Science, no. 7, pp. 159-168, 2012 (Chinese).

[21] L. Li, Z. Tan, N. Li, J. Wang et al., "The contracts for difference between coal producers and electricity generators and its optimal cooperation benefit distributing model based on game theory," Chinese Journal of Management Science, vol. 18, no. 4, pp. 133-139, 2010 (Chinese).

[22] L. Yu, B. Liu, and Y. Ma, "Longitudinal transaction theory and the efficiency of Chinese coal and power enterprise longitudinal transaction," Economic Management, vol. 32, no. 3, pp. 27-33, 2010 (Chinese).

[23] L. Yu and Y. Yu, "Coal-electricity longitudinal relationship arrangement and the government regulation under demand fluctuations," Management World, no. 4, pp. 74-86, 2006 (Chinese).

[24] J.-L. Jiao, H.-Z. Ge, and Y.-M. Wei, "Impact analysis of China's coal-electricity price linkage mechanism: results from a game model," Journal of Policy Modeling, vol. 32, no. 4, pp. 574-588, 2010.

[25] Z. Liu and Y. Ding, "On the establishment and improvement of coal supply emergency response mechanism," China Coal, vol. 34, no. 9, pp. 18-20, 2008 (Chinese).

[26] X. Zhu and D. Zhao, "The problems and countermeasures of coal emergency management in China," China Energy, vol. 33, no. 1, pp. 38-41, 2011 (Chinese).

[27] T. Lv and R. Nie, "Research on the coal reserve mechanism for emergency supply," China Safety Science Journal, vol. 12, no. 18, pp. 68-74, 2008 (Chinese).

[28] T. Lv, Y. Gu, and M. Q. Fang, "Site selection and scale measurement of regional coal reserves: taking jiangsu province as an example," Energy Procedia, vol. 5, pp. 2072-2077, 2011.

[29] Y.-B. Sun, P. Guo, and Y.-J. Wang, "Ascertaining reasonable reserve deal about coal resources," Journal of the China Coal Society, vol. 30, no. 5, pp. 661-664, 2005 (Chinese).

[30] D. Mou, "Extreme-value analysis of China's emergency coal reserve scale," Economic Issues in China, no. 3, pp. 71-78, 2012 (Chinese).

[31] State Development and Reform Commission (SDRC), "Notice about regulating the price of thermal coal," Development and Reform Electricity 299, 2011, (Chinese).

[32] Z. Wang, A. Szolnoki, and M. Perc, "Interdependent network reciprocity in evolutionary games," Scientific Reports, vol. 3, p. 1183, 2013.

[33] A. Szolnoki, Z. Wang, and M. Perc, "Wisdom of groups promotes cooperation in evolutionary social dilemmas," Scientific Reports, vol. 2, p. 576, 2012.

[34] M. Perc, J. Gomez-Gardenes, A. Szolnoki, L. M. Floria, and Y. Moreno, "Evolutionary dynamics of group interactions on structured populations: a review," Journal of the Royal Society Interface, vol. 10, no. 80, Article ID 20120997, 2013.
[35] M. Perc and P. Grigolini, "Collective behavior and evolutionary games-an introduction," Chaos, Solitons \& Fractals, vol. 56, pp. $1-5,2013$.

[36] Z. Wang, A. Szolnoki, and M. Perc, "Evolution of public cooperation on interdependent networks: the impact of biased utility functions," EPL, vol. 97, no. 4, Article ID 48001, 2012.

[37] Z. Wang, A. Szolnoki, and M. Perc, "Optimal interdependence between networks for the evolution of cooperation," Scientific Reports, vol. 3, p. 2470, 2013.

[38] Z. Wang, A. Szolnoki, and M. Perc, "Percolation threshold determines the optimal population density for public cooperation,” Physical Review E, vol. 85, no. 3, Article ID 037101, 2012.

[39] M. Perc and A. Szolnoki, "Coevolutionary games-a mini review," BioSystems, vol. 99, no. 2, pp. 109-125, 2010.

[40] Z. Wang, A. Szolnoki, and M. Perc, "If players are sparse social dilemmas are too: importance of percolation for evolution of cooperation," Scientific Reports, vol. 2, p. 369, 2012.

[41] M. Perc and Z. Wang, "Heterogeneous aspirations promote cooperation in the prisoner's dilemma game," PLOS ONE, vol. 5, no. 12, Article ID e15117, 2010.

[42] G. Aust and U. Buscher, "Vertical cooperative advertising and pricing decisions in a manufacturer-retailer supply chain: a game-theoretic approach," European Journal of Operational Research, vol. 223, no. 2, pp. 473-482, 2012.

[43] H. J. Peng and M. H. Zhou, "Quantity discount supply chain models with fashion products and uncertain yields," Mathematical Problems in Engineering, vol. 2013, Article ID 895784, 11 pages, 2013.

[44] H. J. Peng, M. H. Zhou, and L. Qian, "Supply chain coordination with uncertainty in two-echelon yields," Asia-Pacific Journal of Operational Research, vol. 30, no. 1, Article ID 1250044, 2013.

[45] A. Hafezalkotob and A. Makui, "Supply chains competition under uncertainty concerning player's strategies and customer choice behavior: a generalized Nash game approach," Mathematical Problems in Engineering, Article ID 421265, 29 pages, 2012.

[46] S. Barari, G. Agarwal, W. J. Zhang, B. Mahanty, and M. K. Tiwari, "A decision framework for the analysis of green supply chain contracts: an evolutionary game approach," Expert Systems with Applications, vol. 39, no. 3, pp. 2965-2976, 2012.

[47] D. B. Ni and K. W. Li, "A game-theoretic analysis of social responsibility conduct in two-echelon supply chains," International Journal of Production Economics, vol. 138, no. 2, pp. 303313, 2012.

[48] V. Martinez-de-Albeniz and D. Simchi-Levi, "Supplier-buyer negotiation games: equilibrium conditions and supply chain efficiency," Production and Operations Management, vol. 22, no. 2, pp. 397-409, 2013.

[49] B. X. Li, Y. W. Zhou, J. Z. Li, and S. P. Zhou, "Contract choice game of supply chain competition at both manufacturer and retailer levels," International Journal of Production Economics, vol. 143, no. 1, pp. 188-197, 2013.

[50] Y. H. Guo and J. H. Ma, "Research on game model and complexity of retailer collecting and selling in closed-loop supply chain," Applied Mathematical Modelling, vol. 37, no. 7, pp. 5047-5058, 2013.

[51] A. Szolnoki, M. Perc, and G. Szabo, "Defense mechanisms of empathetic players in the spatial ultimatum game," Physical Review Letters, vol. 109, no. 7, Article ID 078701, 2012.

[52] A. Szolnoki, M. Perc, and G. Szabo, "Accuracy in strategy imitations promotes the evolution of fairness in the spatial ultimatum game," EPL, vol. 100, no. 2, Article ID 28005, 2012. 
[53] H.-J. Peng, M.-H. Zhou, M.-Z. Liu, Y. Zhang, and Y.-B. Huang, "A dynamic optimization model of an integrated coal supply chain system and its application," Mining Science and Technology (China), vol. 19, no. 6, pp. 842-846, 2009. 


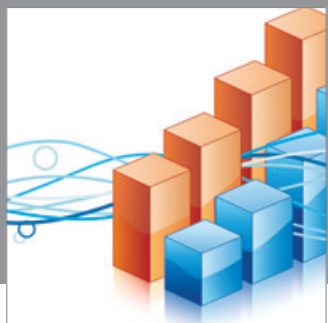

Advances in

Operations Research

mansans

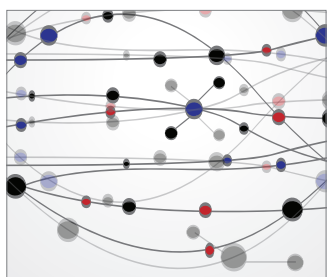

The Scientific World Journal
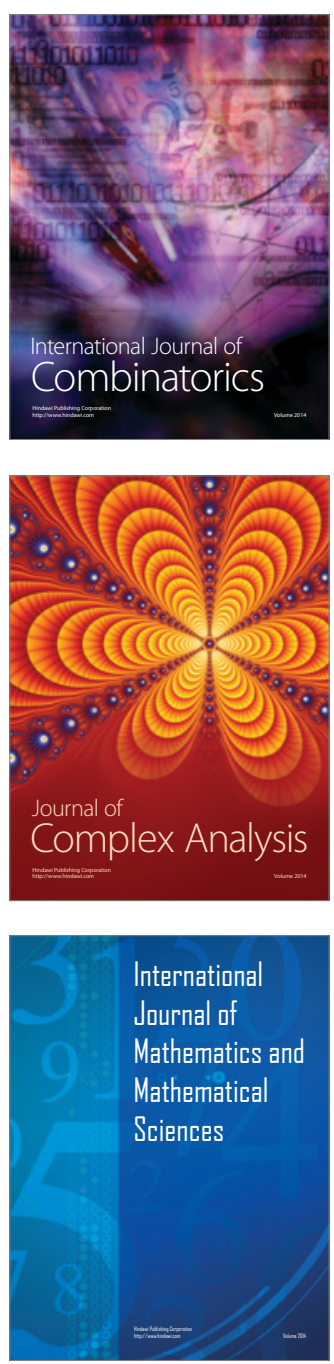
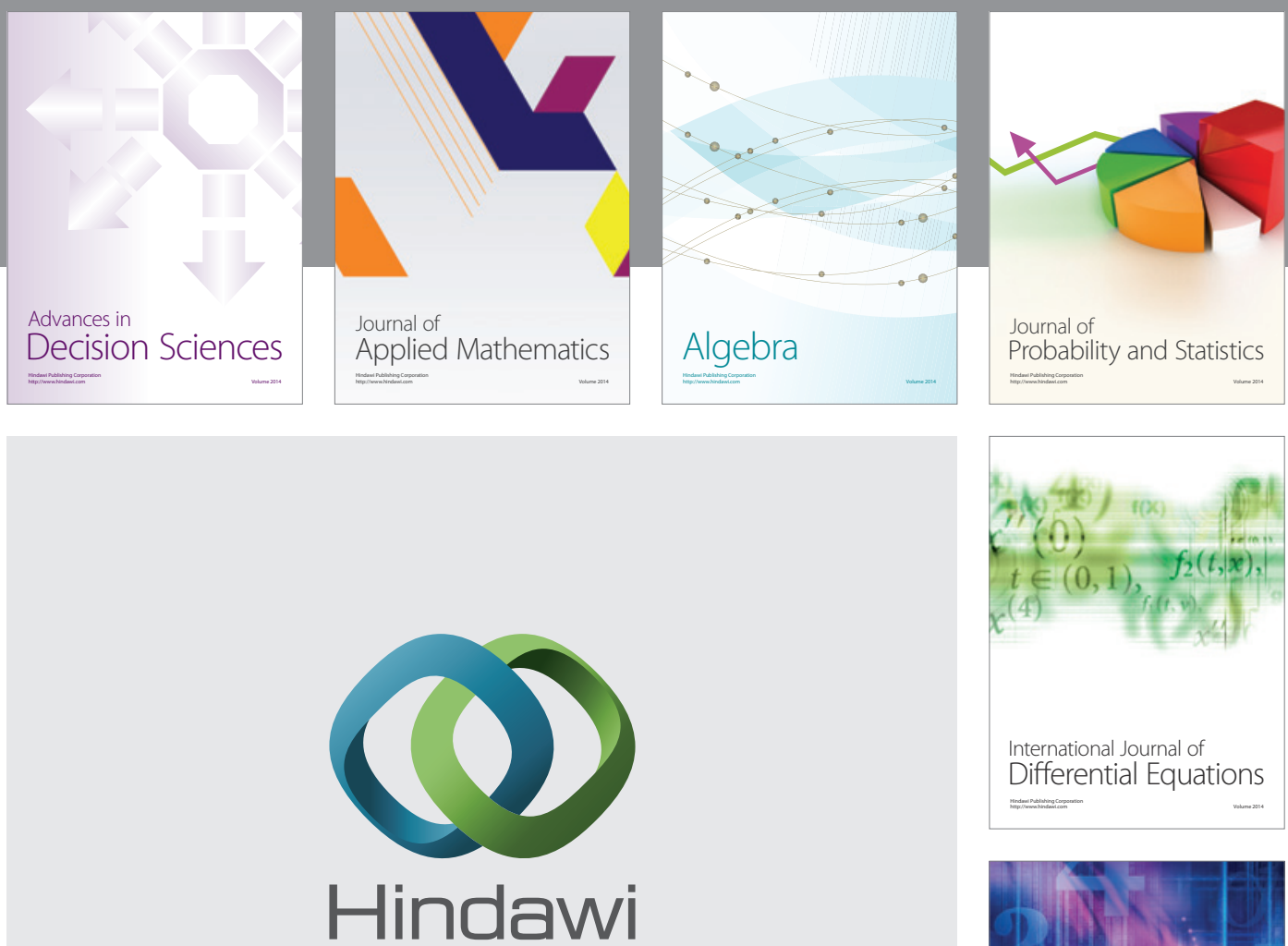

Submit your manuscripts at http://www.hindawi.com
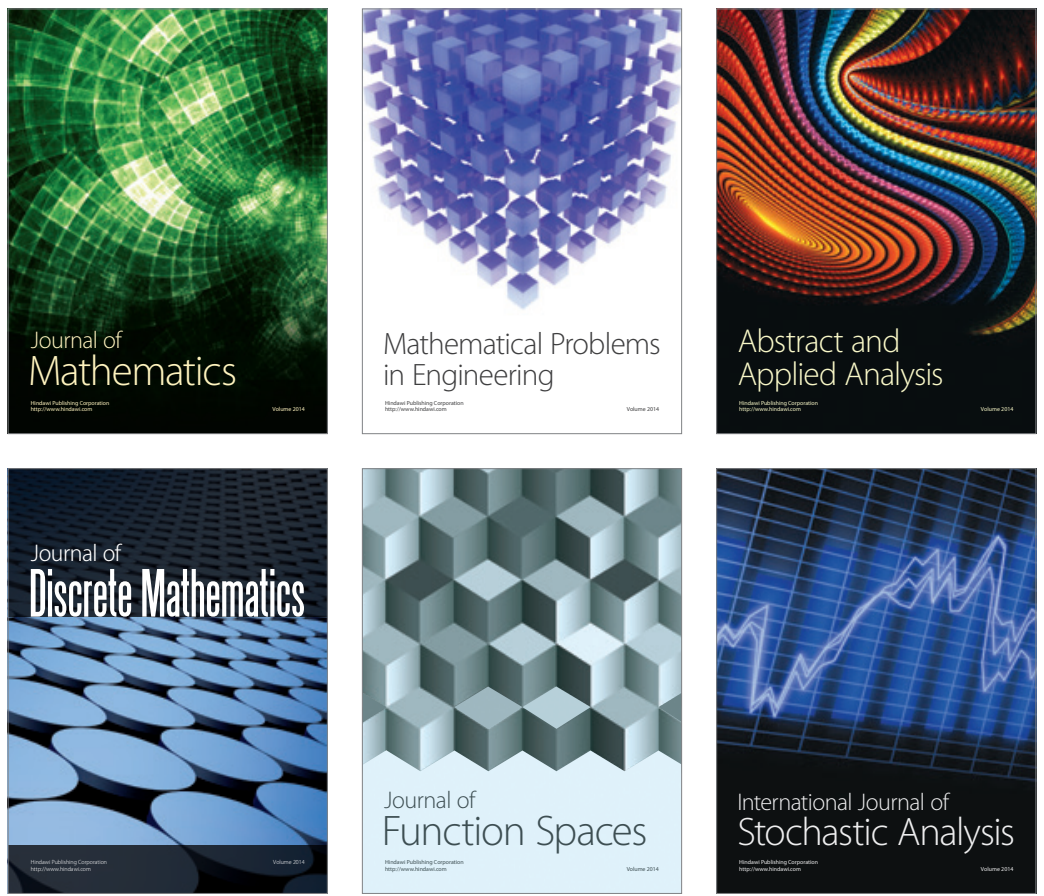

Journal of

Function Spaces

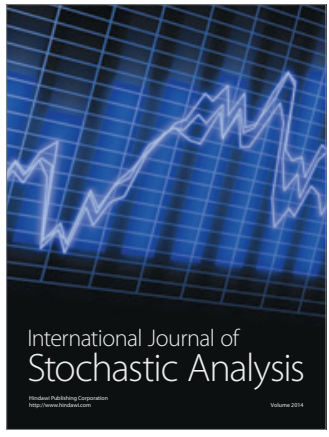

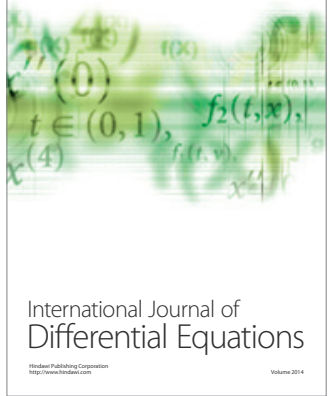
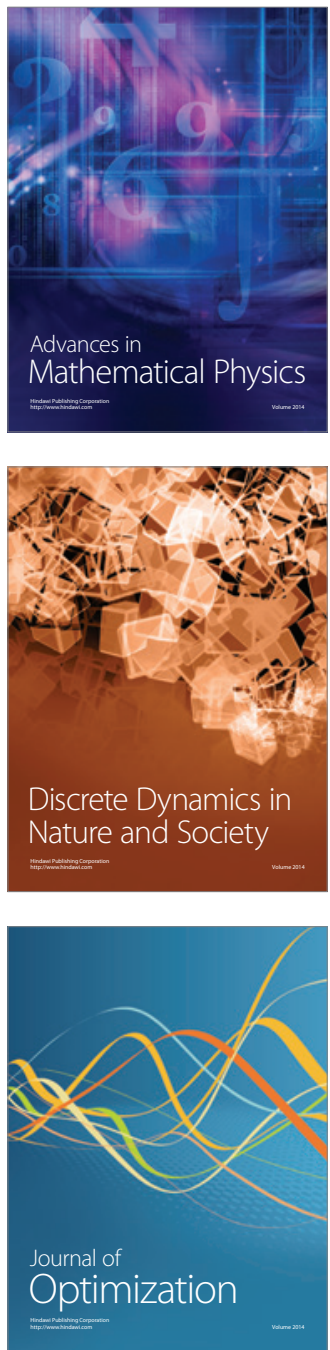